\title{
Densidade de plantio no crescimento e produção de plátano cv. D'Angola na Chapada do Apodi ${ }^{1}$
}

\author{
Rômulo Costa Prata ${ }^{2}$, Jaeveson da Silva ${ }^{3}$, Yuri Bezerra de Lima ${ }^{4}$, Otacílio Filho Alves \\ Anchieta $^{5}$, Renata de Paiva Dantas ${ }^{6}$, Marcelo Bezerra Lima ${ }^{7}$
}

\begin{abstract}
Resumo: O trabalho foi realizado no município de Limoeiro do Norte, Ceará, região de Chapada do Apodi, com o objetivo de avaliar diferentes densidades populacionais de bananeira Plátano na produção e características comerciais dos frutos. No delineamento experimental em blocos casualizados com quatro repetições comparou-se as densidades populacionais de 4.166, 3.125, 2.777 e 2.500 plantas por hectare, em que se manteve distância entre fileiras de 2,0 m e variou as distâncias entre plantas dentro das fileiras, respectivamente, em 1,2 m, 1,4 m, 1,6 m, $1,8 \mathrm{~m}$ e $2,0 \mathrm{~m}$, e a densidade testemunha, no espaçamento de 3,0 $\mathrm{m}$ x 3,0 m, com 1.111 plantas por hectare. As parcelas tiveram seis plantas úteis, com a cultivar D'Angola (AAB). Avaliou-se, na colheita, a altura da planta, o diâmetro do pseudocaule, o número de folhas vivas, a massa fresca do cacho, o número de pencas e o número de frutos e, na segunda penca, a massa e o número de frutos e, nos frutos, a massa unitária, o comprimento e o perímetro. A maior densidade populacional de plantas propiciou a maior produtividade, com incremento de $263 \%$, sem alterar características comerciais dos frutos.
\end{abstract}

Palavras-chave: Musa spp; População de plantas; Altura da planta; Rendimento de cacho.

\section{Density of planting on the growth and production of plantain cv. D'Angola in the Chapada do Apodi}

\begin{abstract}
The work was carried out in the municipality of 'Limoeiro do Norte', 'Ceará', in the region of 'Chapada do Apodi', with the objective of evaluating different population densities of banana plantain in the production and commercial characteristics of fruits. In the experimental design in randomized blocks with four replicates, the population densities of 4,166, 3,125, 2,777 and 2,500 plants per hectare were compared, where distance between rows of $2.0 \mathrm{~m}$ was maintained and the distances between plants within the rows respectively, at $1.2 \mathrm{~m}, 1.4 \mathrm{~m}, 1.6 \mathrm{~m}, 1.8 \mathrm{~m}$ and $2.0 \mathrm{~m}$, and the control density, at spacing of $3.0 \mathrm{mx} 3.0 \mathrm{~m}$, with 1111 plants per hectare. The plots had six useful plants, with the cultivar 'D'Angola' (AAB). The height of the plant, the diameter of the pseudostem, the number of live leaves, the fresh mass of the bunch, the number of leaves and the number of fruits were evaluated at harvest, and in the second hand the mass and number of fruits and, in the fruits, the unit mass, the length and the perimeter. The higher population density of plants provided the greatest productivity, with an increase of $263 \%$, without changing the commercial characteristics of the fruits.
\end{abstract}

Key words: Musa spp; Plant population; Plant height; Bunch yield.

\footnotetext{
${ }^{1}$ Submetido em 30/12/2017 e aprovado em 05/03/2018

${ }^{2}$ Graduando em Agronomia, Universidade Federal Rural do Semi-Árido (UFERSA), Mossoró-RN, CEP: 59625-900; E-mail: romulocostaprata@hotmail.com

${ }^{3}$ Doutor em Fitotecnia; Pesquisador, Embrapa Mandioca e Fruticultura (CNPMF), Cruz das Almas-BA, CEP: 44.380-000; E-mail: jaeveson.silva@embrapa.br

${ }^{4}$ Graduando em Agronomia, Universidade Federal Rural do Semi-Árido (UFERSA), Mossoró-RN, CEP: 59625-900; E-mail: yuribzdlima@hotmail.com

${ }^{5}$ Graduando em Agronomia, Universidade Federal Rural do Semi-Árido (UFERSA), Mossoró-RN, CEP: 59625-900; E-mail: filhooanchieta@gmail.com

${ }^{6}$ Engenharia Florestal; Mestranda, Universidade Federal Rural do Semi-Árido (UFERSA), Mossoró-RN, CEP: 59625-900; E-mail: renatadepaiva@hotmail.com

${ }^{7}$ Mestre em Ciências Agrárias; Pesquisador, Embrapa Mandioca e Fruticultura (CNPMF), Cruz das Almas-BA, CEP: 44.380-000; E-mail: marcelo.lima@embrapa.br
} 


\section{Introdução}

A produção de plátanos apresenta-se como alternativa aos produtores, pois sua oferta não atende à demanda, faltando a fruta na maioria das centrais de abastecimento do Brasil. Um estimulo através de políticas agrícolas e trabalhos de introdução da cultura em áreas de produção de banana, favoreceriam a sua adoção pelos produtores, sendo mais uma alternativa as cultivares tradicionais de 'Prata' e 'Pacovan', e, geralmente, os plátanos com maior valor comercial. As estatísticas de produção brasileiras não especificam dados agrícolas por tipo de banana comercializada, apesar da presença de nichos de mercados importante para os plátanos (Bahia e Sergipe), impossibilitando identificar a expressiva geração de renda aos produtores e o atendimento a rede varejistas local e de exportação com a cultura (Bustamante, 2015).

No Brasil, entretanto, precisa-se difundir tecnologias especificas para os plátanos (bananeira tipo Terra, AAB), para substituir as adaptações introduzidas de sistemas de produção gerados e utilizados para o cultivo de bananas tradicionais, principalmente do tipo Prata, pois apresentarem hábito, porte, ciclo e determinantes genéticos diferenciados (Karamura et al., 2013), implicando em produções comerciais e resultados experimentais indesejáveis (Martínez et al., 2008). Nas regiões tradicionais de cultivo dos plátanos no país, em que a maioria ocorre com a cv. Terra Maranhão, visa-se obter duas a três colheitas, isto é, manejada como uma típica cultura semiperene, mesmo percebendo, após o primeiro ciclo de produção, redução do estande, no vigor das plantas e produtividade (Alves, 2001).

O aumento da densidade de plantas e a modificação do arranjo espacial no campo, para viabilizar o cultivo em um único ciclo, são estratégias que trazem ganhos econômicos, tanto em culturas perenes como em culturas anuais. Pesquisas apontam que sistemas de produção adensados com ciclo anual de cultivo (uma única colheita) podem tornar a cultura mais eficiente no uso dos recursos ambientais e dos fatores de produção em relação ao sistema tradicional de produção (Cayón et al., 2004; Belalcazar e Espinoza, 2000).

O sistema de plantio com altas densidades de plantas, com manejo das unidades produtivas num único ciclo de produção e em blocos de cultivo escalonado, pode constituir-se em uma alternativa rentável, passando ao produtor incremento significativo no rendimento, otimização de custos, o aproveitamento de uma grande quantidade de 'filhos' emitidos para atender novos plantios e na redução de pressões de doenças e pragas acumuladas em cultivos com mais de um ciclo, tais como as Sigatokas e moleque da bananeira. As plantas daninhas também ficam em desvantagem de competição, há maior incremento de biomassa (C orgânico) por unidade de área e uso mais eficiente do espaço geográfico, isto é, sem necessidade de abrir grandes espaços para o plantio (Cortazar et al., 2017; Sarrwy et al., 2012; Biswas e Kuwar, 2010; Rosales et al., 2008; Martínez et al., 2008; Cayón et al., 2004; Belalcázar, 2002).

O plátano cv. D'Angola apresenta porte médio, cultivar interessante para o semiárido que utiliza irrigação, sem a necessidade de escoramento exigido pela maioria dos plátanos, considerando que é ambiente que induz maior crescimento em altura da planta e com ocorrência de ventos que favorecem o tombamento de plantas. Os frutos de sabor agradável e 'graúdos', compensam o cacho (tipo 'chifre') com poucas pencas, tornando-se atrativo para comercialização a mercados novos e tradicionais (Alves, 2001). O objetivo do trabalho foi avaliar a produção de plátano cv. D'Angola em altas densidades de plantio, em cultivo irrigado em ambiente semiárido de Chapada do Apodi.

\section{Material e Métodos}

O trabalho foi realizado em área comercial da Fazenda Frutacor LTDA, no Distrito de Irrigação Jaguaribe-Apodi (DIJA), sediada em Limoeiro do Norte, distante $207 \mathrm{~km}$ de Fortaleza, Ceará, abrangendo região de Chapada do Apodi, localizado nas coordenadas $5^{\circ} 11^{\prime} 38^{\prime \prime} \mathrm{S}, 37^{\circ} 52^{\prime} 21^{\prime \prime}$ $\mathrm{W}$, e altitude de $110 \mathrm{~m}$. A região apresenta médias anuais de temperatura de $28,5^{\circ} \mathrm{C}$ e precipitação pluviométrica de $772 \mathrm{~mm}$. A classificação climática, segundo Köppen, é do tipo BSwh', ou seja, muito quente e semiárido, com estação chuvosa no verão se atrasando para o outono. $\mathrm{O}$ solo é classificado como Argissolo VermelhoAmarelo (EMBRAPA, 2013).

$\mathrm{O}$ experimento foi realizado em blocos casualizados com quatro repetições, com parcelas compostas de 20 plantas e seis plantas úteis 
(centrais), e os tratamentos representados por cinco densidades de plantio, 4.166, 3.125, 2.777 e 2.500 plantas por hectare, onde manteve-se a distância entre fileiras de 2,0 m e entre plantas dentro das fileiras variando, respectivamente, de $1,2 \mathrm{~m}, 1,4 \mathrm{~m}, 1,6 \mathrm{~m}, 1,8 \mathrm{~m}$ e $2,0 \mathrm{~m}$. Considerouse também um tratamento testemunha, utilizando o espaçamento de $3,0 \mathrm{~m}$ x $3,0 \mathrm{~m}$, com 1.111 plantas por hectare, que é representativo para o cultivo dos plátanos (Cortazar et al., 2017). O plantio foi realizado no dia 5 de novembro de 2014, com o plátano cv. D'Angola, utilizando-se mudas micropropagadas provenientes da Embrapa Mandioca e Fruticultura, em Cruz das Almas, BA, e preparo final destas mudas em viveiro da empresa Frutacor Ltda., até a idade de 75 dias. As covas tiveram dimensões de $40 \mathrm{~cm} \mathrm{x}$ $40 \mathrm{~cm}$ x $40 \mathrm{~cm}$, abertas em sulcos de plantio.

Nas covas de plantio, aplicou-se fósforo na forma de monoamônio fostato - MAP $(300 \mathrm{~g})$ com adição de $20 \mathrm{~L}$ de composto orgânico. Dez adubações de cobertura foram realizadas por fertirrigação, em intervalo aproximada de 40 dias, aplicando NPK (FTH Banana $\left.{ }^{\circledR}, 15-7-30\right)$, até à colheita dos cachos (média de 313 dias). A irrigação, do tipo localizada com uma fita gotejadora por fileira, iniciou com a aplicação diária de $8 \mathrm{~mm}$ de água até estabelecimento da planta (seis meses), com posterior redução para 6 mm (devido à escassez hídrica na região).

Controlou-se somente a broca do rizoma (Cosmopolites sordidus Germ.), com aplicação de Counter® (inseticida-nematicida à base de Terbufós), sempre que necessário, até o início da emissão dos cachos (média de 217 dias). As plantas infestantes foram controladas utilizando enxada e herbicidas registrados para a cultura, nas ocasiões de alta população de plantas.

Avaliou-se, em um único ciclo de produção, por ocasião da colheita, as características de crescimento (altura de plantas, medida do colo até a base da ráquis; diâmetro do pseudocaule, medido a $30 \mathrm{~cm}$ do colo da planta, e número de folhas vivas) e de produção do cacho (tempo para a colheita, massa fresca, número de pencas, número de frutos, massa fresca da segunda penca, número de frutos na segunda penca e a massa fresca unitária, comprimento e perímetro também de frutos da segunda penca). A colheita foi iniciada em 25.08.2015.
Os dados foram submetidos à análise de variância (teste F), teste de Dunnet em relação ao tratamento testemunha e análise de regressão (teste $\mathrm{t}$ de Student, para coeficientes) sem o tratamento testemunha, considerando a probabilidade de $5 \%$ de erro, utilizando o software estatístico Sisvar (Ferreira, 2011).

\section{Resultados e Discussão}

Para as características de crescimento, apenas a altura de planta respondeu, positiva e linearmente, com o aumento das densidades de plantio (Tabela 1 e Figura 1). O porte da planta e considerando o adensamento máximo realizado dentro da linha de plantio pode ter mantido igualitário o diâmetro do pseudocaule, mesmo em altas densidades (Pereira, 2000). Observou-se, para a mesma cultivar, sendo que com duas plantas por cova, diferenças de diâmetro do pseudocaule influenciado pela densidade de plantio, em condição irrigada em Cruz das Almas, Bahia (Lima et al. 2015; Coelho et al., 2013). Neste trabalho e no conduzido por Dantas (2010), em Ipanguaçu (RN), observou-se médias superiores de diâmetro de pseudocaule ao que foi registrado para a cultura (Alves, 2001), provavelmente pela melhor qualidade do solo para a bananeira e maior disponibilidade de água na época de condução do experimento (Coelho et al., 2013). Para a bananeira plátano cv. 'Comprida Verdadeira', Moura et al. (2002) observou diferenças no diâmetro do pseudocaule com as densidades de plantio, sendo maior na densidade 2.500 plantas e menor quando em 1.666 plantas, provavelmente induzido pela maior incidência de luz em espaçamentos maiores e promovendo maior crescimento das plantas.

A altura de plantas (Tabela 1 e Figura 1) foi superior a testemunha entre as maiores densidades de plantio, indicando que houve a competição por luz e induzindo esse crescimento para a cultivar (estiolamento), que variou de 52 $\mathrm{cm}(16 \%)$ a $79 \mathrm{~cm}$, sendo o maior ganho para a maior densidade de plantio. Em cultivares de plátano com porte baixos, como a cv. D’Angola, não se tem observado significativo em parâmetros de crescimento quando se compara pequenas variações nos espaços entre plantas (Ñez e Tavira, 1999), somente em densidades excessivamente altas, superiores a 5 mil plantas por hectare (Kesavan et al., 2002). O incremento do ganho em altura observado entre as diferentes densidades de 
plantio, se excessivo, pode ser aspecto negativo, considerando regiões com ocorrência de ventos fortes, que favorece o tombamento de plantas, como vem ocorrendo para a cv. Pacovan (bananeira tipo Prata) na região da Chapada do Apodi, e atualmente sendo substituída por bananeiras porte menor. Plantas mais alta também dificultam a colheita e favorece danos aos cachos (Faria et al., 2010). Para a densidade de 1.111 plantas por hectare, em condição semiárida e irrigada, Faria et al. (2010) obteve altura de plantas de 3,16 m e, Dantas (2010), na densidade de 1.666 plantas, no Vale do Açu (RN), observou altura de $3,89 \mathrm{~m}$ em primeiro ciclo, ambos utilizando o cv. 'D'Angola'.

Tabela 1 Resumo da análise de variância para dados de crescimento de plantas da bananeira tipo Plátano cv. D'Angola em função da densidade de plantio

\begin{tabular}{|c|c|c|c|c|}
\hline \multirow{2}{*}{ FV } & \multirow{2}{*}{ GL } & \multicolumn{3}{|c|}{ Quadrados médios ${ }^{1}$} \\
\hline & & DPC & $\mathbf{A P}$ & NFV \\
\hline Densidade & 5 & $8,49^{\text {ns }}$ & $2879,31 *$ & $0,50^{\mathrm{ns}}$ \\
\hline Bloco & 3 & $6,84^{\mathrm{ns}}$ & $380,07^{\mathrm{ns}}$ & $0,32^{\mathrm{ns}}$ \\
\hline Erro & 15 & 3,05 & 689,79 & 0,78 \\
\hline C.V. $(\%)$ & & 7,7 & 7,0 & 9,0 \\
\hline \multirow{2}{*}{\multicolumn{2}{|c|}{$\begin{array}{l}\text { Regressão } \\
\text { Densidade plantio }{ }^{2}\end{array}$}} & ns & $* *$ & $\mathrm{~ns}$ \\
\hline & & \multicolumn{3}{|c|}{ Médias } \\
\hline \multicolumn{2}{|l|}{1.111 - Test. } & 23,2 & 322,6 & 10,2 \\
\hline \multicolumn{2}{|l|}{2.500} & 24,5 & $383,8^{*}$ & 9,3 \\
\hline \multicolumn{2}{|l|}{2.777} & 22,1 & $375,0 *$ & 9,6 \\
\hline \multicolumn{2}{|l|}{3.125} & 21,5 & 371,1 & 9,7 \\
\hline \multicolumn{2}{|l|}{3.571} & 20,8 & $383,1 *$ & 9,9 \\
\hline \multicolumn{2}{|l|}{4.166} & 23,9 & $401,8^{*}$ & 10,2 \\
\hline \multicolumn{2}{|c|}{ Médias } & 22,7 & 372,9 & 9,8 \\
\hline \multicolumn{5}{|c|}{ 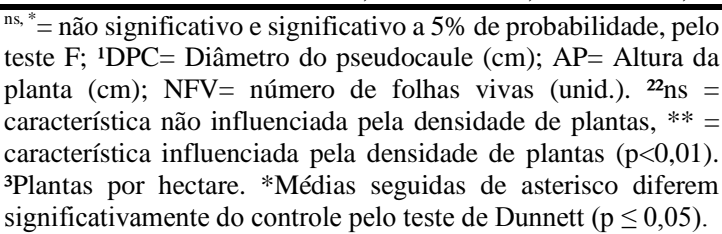 } \\
\hline
\end{tabular}

A manutenção da quantidade de folhas (Tabela 1) até a colheita favorece o desenvolvimento dos cachos, uma vez que após a diferenciação floral as emissões desses órgãos são cessadas (Moreira, 1987). A quantidade de folhas vivas pode ter sido favorecida pela condição climática da região, com a alta incidência de luz durante todo o ano, e o tipo de irrigação (localizada por gotejamento) e período prolongado de baixas precipitações pluviométricas (baixa umidade do ar), aspectos que não favorecem o desenvolvimento de fungos patogênicos como a sigatoka-amarela (Cordeiro, 2000). Também, o menor porte da cv. D'angola pode ter desfavorecido a ocorrência de danos pelo vento, como o 'rasgamento' e queima (ar quente), que ocasiona morte precoce das folhas. Moura et al. (2002), trabalhando com Plátano cv. Comprida Verdadeira, em três diferentes densidades (2.500, 2.000 e 1.666 plantas por hectare), na zona da mata sul pernambucana (zona mais úmida), obtiveram número de folhas na colheita inferior aos obtidos nesse trabalho (média de 6,9 folhas).

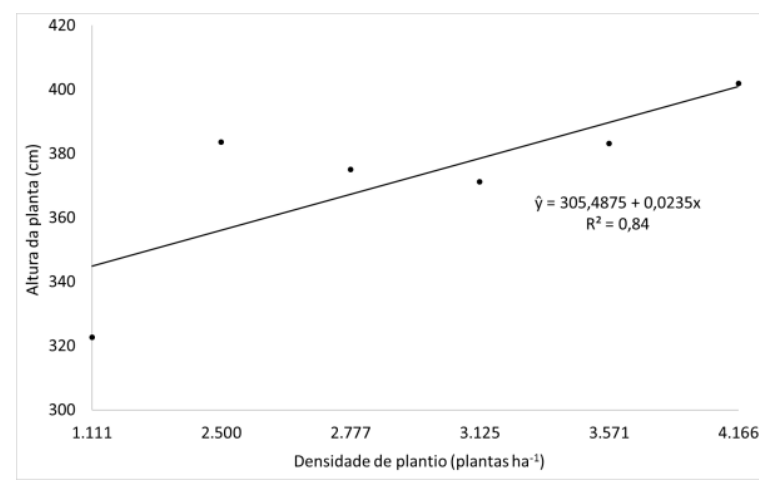

Figura 1 Altura de planta na colheita plátano cv. D’Angola em função da densidade de plantio.

Os resumos das análises de variância e de médias de dados de produção podem ser observados na Tabela 2, com diferença significativa considerando o teste $F(p<0,05)$, somente para rendimento do cacho (Figura 2) quanto a variação da densidade de plantas, comum ao que se é observado quando se avalia a característica em outros trabalhos com plátanos (Cortazar et al., 2017; Cayon et al., 2004; Delgado et al., 2008). A não variação nos parâmetros de produção número de frutos e massa do cacho permitiu que esses frutos mantivessem características comerciais de dimensão e massa unitária, nas densidades avaliadas neste trabalho (Tabela 3). Como mencionado, em pequenos incrementos na distância entre plantas, principalmente com cultivares de plátanos de porte menores, não se tem observado variações significativas em parâmetros de crescimento e componentes de produção, mesmo com altos rendimentos do cacho (Añez e Tavira, 1999), exceto em densidades excessivamente altas, superiores a 5 mil plantas por hectares (Kesavan et al., 2002), pressupondo-se também a pouca influência da competição entre plantas nas características do fruto na cv. D'Angola (Andrade Neto et al., 2015).

Neste trabalho observou-se uma média de sete pencas por cacho, semelhante ao observado na literatura (Almeida et al., 2014; Moura et al., 2002; Alves, 2001), apesar de que, numa 
população de 1.666 de plantas por hectare $(3,0 \mathrm{~m}$ x 2,0 m), em Ipanguaçu (RN), Dantas (2010) obteve média de oito pencas por cacho no primeiro e demais ciclos de cultivo, também em plantas da cv. D'Angola.

Tabela 2 Resumo da análise de variância para dados de produção da bananeira tipo Plátano cv. D’Angola em função da densidade de plantio

\begin{tabular}{|c|c|c|c|c|c|c|c|}
\hline \multirow[t]{2}{*}{$\mathrm{FV}$} & \multirow[t]{2}{*}{ GL } & \multicolumn{6}{|c|}{ Quadrados médios ${ }^{1}$} \\
\hline & & NP & $\mathrm{NF}$ & $\mathrm{MP}$ & $\mathrm{MC}$ & $\mathrm{RC}$ & TC \\
\hline Dens. & 5 & $0,34^{\mathrm{ns}}$ & $33,47^{\mathrm{ns}}$ & $120448,39^{\mathrm{ns}}$ & $5,06^{\mathrm{ns}}$ & $569,34^{* *}$ & $122,01^{\mathrm{ns}}$ \\
\hline Bloco & 3 & $0,17^{\mathrm{ns}}$ & $3,38^{\mathrm{ns}}$ & $35874,93^{\mathrm{ns}}$ & $0,23^{\mathrm{ns}}$ & $6,74^{\mathrm{ns}}$ & $18,65^{\mathrm{ns}}$ \\
\hline Erro & 15 & 0,25 & 11,76 & 208069,35 & 2,10 & 24,73 & 65,37 \\
\hline $\mathrm{CV}(\%)$ & & 7,2 & 11,9 & 17,4 & 12,8 & 15,6 & 2,6 \\
\hline Análise regressão ${ }^{2}$ & & ns & ns & $\mathrm{ns}$ & ns & $* *$ & ns \\
\hline Densidade plantio $^{3}$ & & & & Médias & & & \\
\hline 1.111 & & 7,6 & 33,9 & 2.699 & 11,5 & 12,8 & 305,7 \\
\hline 2.500 & & 6,8 & 28,5 & 2.725 & 11,7 & $29,2 *$ & 313,6 \\
\hline 2.777 & & 6,8 & 27,3 & 2.435 & 9,3 & $25,7 *$ & 310,7 \\
\hline 3.125 & & 6,9 & 30,2 & 2.851 & 12,6 & $39,4 *$ & 309,7 \\
\hline 3.571 & & 6,9 & 25,6 & 2.406 & 11,8 & $37,6^{*}$ & 314,2 \\
\hline 4.166 & & 7,1 & 27,8 & 2.622 & 11,2 & $46,5^{*}$ & $322,1 *$ \\
\hline Médias & & 7,0 & 28,9 & 2.623 & 11,3 & 31,8 & 312,6 \\
\hline
\end{tabular}

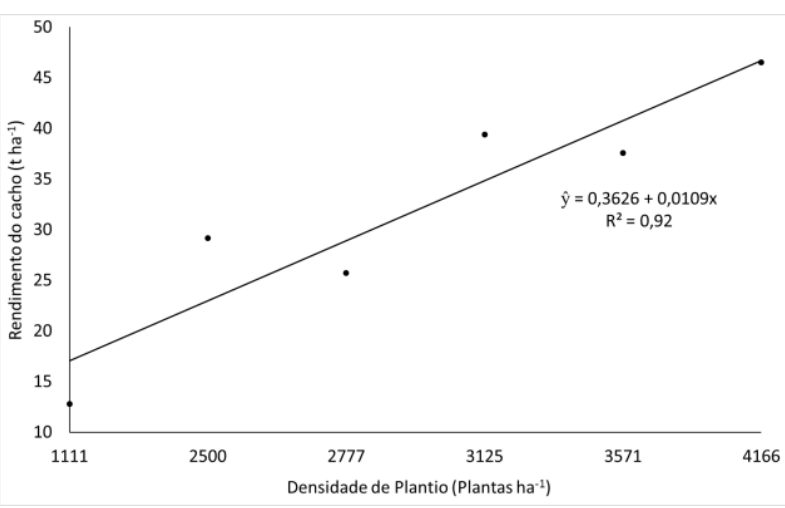

Figura 2 Rendimento do cacho na colheita do plátano cv. D’Angola em função da densidade de plantio.

A quantidade de frutos por cacho (Tabela 2) observada foi a esperada para a cultivar (Alves, 2001) e a observada em outros trabalhos realizados no Recôncavo Baiano e Bioma Amazônico (Moura et al., 2002; Almeida et al., 2014), no entanto, Dantas (2010) obteve para a cv. D'Angola, em Ipanguaçu (RN), número de frutos por cacho de 39,6 no primeiro ciclo, valor superior ao que foi observado neste trabalho.

A massa fresca da segunda penca foi superior ao encontrado por Dantas (2010), que obteve massa em até $1.841,5 \mathrm{~g}$, também no primeiro ciclo, e por Moura et al (2002), com massas variando de $1.970 \mathrm{~g}$ a 2.385,7 g para as maiores e menores densidades de plantas avaliadas. A bananeira tipo Terra cv. D'Angola tem como características poucos frutos por penca, porém estes são grandes e pesados, com as primeiras pencas apresentando em média oito frutos e a última apenas um (Alves, 2001).

A massa fresca do cacho (Tabela 2) foi inferior aos obtidos por Moura et al. (2002), que observou variação de 14,4 kg (>27\%) a 17,8 kg (>57\%), em 2.500 e 1.666 plantas por hectare, respectivamente, e por Dantas (2010), de $16,5 \mathrm{~kg}$ $(>46 \%)$, em 1.666 plantas por hectare. A maior qualidade do solo para a banana e disponibilidade de água nas épocas de condução do trabalho, geralmente observado em áreas com maior tradição com a cultura, beneficia significativamente a produção (Coelho et al., 2013). Essa variável é importante para o produtor, pois cachos pesados refletem ganhos econômicos, já que a comercialização, em sua maioria, é realizada por pesagem. Para a cv. Comprida Verdadeira, em Rio Branco (AC), Almeida et al. (2014) obtiveram variação no peso do cacho de 17,7 a $19,6 \mathrm{~kg}$, com as densidades de 1.666 e 
1.111 plantas por hectare, respectivamente. $\mathrm{O}$ controle da irrigação, que foi reduzida de $8 \mathrm{~mm}$ para $6 \mathrm{~mm}$, devido ao período prolongado de 'seca', pode ter ocasionado pesos menores no cacho ao que se observado em algumas pesquisas, apesar que dentre os principais plátanos cultivados no Brasil, a cv. D’Angola é a que demanda menor quantidade de água durante o seu ciclo (Coelho et al., 2013).

Tabela 3 Resumo da análise de variância e média para dados de frutos do Plátano cv. D’Angola em função da densidade de plantio

\begin{tabular}{|c|c|c|c|c|}
\hline \multirow{2}{*}{$\begin{array}{l}\text { Fonte de } \\
\text { variação }\end{array}$} & \multirow{2}{*}{ GL } & \multicolumn{3}{|c|}{ Quadrados médios ${ }^{1}$} \\
\hline & & CF & PF & MF \\
\hline Dens. & 5 & $4,94^{\mathrm{ns}}$ & $0,47^{\mathrm{ns}}$ & $5187,50^{\mathrm{ns}}$ \\
\hline Bloco & 3 & $5,69^{\mathrm{ns}}$ & $0,70^{\mathrm{ns}}$ & $6539,56^{*}$ \\
\hline Erro & 15 & 1,87 & 0,25 & 1916,66 \\
\hline C.V. $(\%)$ & & 4,4 & 3,1 & 10,6 \\
\hline \multirow{2}{*}{\multicolumn{2}{|c|}{$\begin{array}{l}\text { Análise } \\
\text { regressão } \\
\text { Densidade plantio }^{3} \\
\end{array}$}} & ns & ns & ns \\
\hline & & \multicolumn{3}{|c|}{ Médias } \\
\hline 1.111 & & 29,3 & 16,0 & 353,0 \\
\hline 2.500 & & $32,4 *$ & 16,7 & $441,8 *$ \\
\hline 2.777 & & 31,3 & 16,3 & 414,3 \\
\hline 3.125 & & 32,0 & 17,0 & $449,4 *$ \\
\hline 3.571 & & 32,0 & 16,5 & 431,8 \\
\hline 4.166 & & 30,8 & 16,3 & 393,6 \\
\hline Médias & & 31,3 & 16,5 & 414,0 \\
\hline \multicolumn{5}{|c|}{$\begin{array}{l}\mathrm{ns},{ }^{*}=\text { não significativo e significativo a } 5 \% \text { de } \\
\text { probabilidade, pelo teste } \mathrm{F} ;{ }^{1} \mathrm{CF}=\text { comprimento do fruto } \\
(\mathrm{cm}) ; \mathrm{PF}=\text { perímetro do fruto }(\mathrm{cm}) ; \mathrm{MF}=\text { massa fresca do } \\
\text { fruto }(\mathrm{g}) .{ }^{2} \mathrm{~ns}=\text { característica não influenciada pela } \\
\text { densidade de plantas; }{ }^{3 P} \text { Plantas por hectare. *Médias } \\
\text { seguidas de asterisco diferem significativamente do } \\
\text { controle pelo teste de Dunnett }(\mathrm{p}<0,05) \text {. }\end{array}$} \\
\hline
\end{tabular}

As produtividades, observado com o rendimento do cacho (Tabela 2 e Figura 2), nesse trabalho se comportando de forma linear as densidades de plantio, apresentou incremento de $263 \%$, partindo de $12,8 \mathrm{tha}^{-1}$ até $46,5 \mathrm{t} \mathrm{ha}^{-1}$, muito superior a produtividade alcançada com esta cultivar em plantios comerciais em condições favoráveis, que é de 15 a $20 \mathrm{t} \mathrm{ha}^{-1}$ ciclo $^{-1}$ (Alves, 2001). Para o plátano cv. Barraganete, avaliada no Equador, observou-se efeito quadrático no rendimento do cacho variando a densidade de plantio de 833 para 3.333 plantas por hectare, com pico de produção na densidade de 1.667 plantas por hectare (Cortazar et al., 2017). Em três densidades, Moura et al. (2002) não obteve diferenças para esta característica, em região de Zona da Mata em Pernambuco e irrigado por aspersão subcopa. Para outras bananeiras como as cultivares Nanicão, Prata Anã e Thap Maeo observou-se aumento na produtividade do cacho com o aumento da população de plantas (PEREIRA et al., 2000; SCARPARE FILHO; KLUGE, 2001; MOREIRA et al., 2007). Cortazar et al. (2017) observaram aumento de $115 \%$ na produtividade do cacho (de $10,1 \mathrm{t} \mathrm{ha}^{-1}$ para $21,8 \mathrm{t}$ ha $\left.^{-1}\right)$.

Um maior adensamento de plantas, até atingir o ápice de produtividade, pode favorecer a quantidade, porém a qualidade dos frutos pode ficar prejudicada, aumentando os frutos classificados como de segunda categoria, perdendo na agregação de valor dos frutos após classificação. Neste trabalho, os frutos mantiveram a qualidade comercial também nas maiores densidades, algo também observado em cultivos consorciados da cv. D'Angola com Açaizeiro (ANDRADE NETO et al, 2015). No entanto, foi observado com a densidade testemunha (1.111 plantas por hectares), em que as plantas estavam mais espaçadas e, portanto, sem efeito protetor, maior incidência de ataque de fungos nas extremidades dos frutos (frutos tipo 'charuto'), desqualificando-os comercialmente, tendo como causa provável danos causados pelos ventos quentes, ferindo os frutos nas pontas e favorecendo o ataque das pragas (KESAVAN et al. (2002).

O tempo de colheita do cacho (Tabela 2) não foi significativo entre as densidades de plantio considerando o teste $F(p>0,05)$, sendo de aproximadamente 10 meses de idade da planta, embora $\mathrm{o}$ teste de Dunnet $(\mathrm{p}<0,05)$ tenha apontado um atraso de aproximadamente 16 dias na colheita de cachos quando sob densidade de plantio de 4.166 planta por hectare. Maior tempo para colheita do cacho pode ser conferido pelo aumento da população de plantas, por competição entre as plantas por água, luz e nutrientes, mas, principalmente radiação solar, favorecendo o estiolamento, redução do diâmetro do pseudocaule (não observado neste trabalho) e gasto de energia em crescimento, o que favorece, consequentemente, atrasando a saída da inflorescência (Kesavan et al., 2002). Scarpare Filho e Kluge (2001), com a cv. Nanicão, não verificaram diferenças no primeiro ciclo de colheita em quatros densidades e nas distribuições de plantio triangular e retangular, porém no segundo ciclo, houve maior tempo de colheita para o maior adensamento e maior precocidade na menor densidade para ambas 
distribuições de plantio. Também foram observados por Moura et al. (2002) diferenças de dias do plantio a colheita para três densidades, com maior ciclo (11 dias) quando houve maior número de plantas por área. O mesmo foi observado por Moreira et al. (2007), para a cv. 'Thap Maeo. O tempo de colheita ou o ciclo de cultivo do plátano cv. D’Angola, neste trabalho, foi 71 dias mais precoce que o observado para em Cruz das Almas, Bahia (COELHO et al., 2013), considerando fatores edafoclimáticos da Chapada do Apodi que favorecem essa precocidade.

O comprimento do fruto (Tabela 3) foi superior aos obtidos por Almeida et al. (2014), com a cv. D'Angola avaliada em duas densidades de plantio, obtendo frutos com comprimento médio de $27,2 \mathrm{~cm}$. Faria et al. (2010), para a mesma cultivar em condições semiáridas, obteve frutos com 26,1 cm de comprimento, e Dantas (2010), com 29,3 cm. Lima (2015) obteve frutos com comprimento e diâmetro menores quando aumentou a densidade de plantio. Os valores obtidos foram superiores ao encontrados por Almeida et al. (2014), e que também não encontrou diferenças entre frutos para três populações de plantas, obtendo uma variação de $0,12 \mathrm{~cm}$, e diâmetro médio de $5,0 \mathrm{~cm}$. Por outro lado, Faria et al. (2010) observaram maior diâmetro na cv. Terra D'Angola, com 4,6 cm, conduzindo experimento com cinco cultivares de bananeira tipo Terra no Município de Guanambi, BA. Os valores apresentados indicam frutos com adequado padrão para comercialização, com 31,3 $\mathrm{cm}$ de comprimento e $16,5 \mathrm{~cm}$ de perímetro $(5,2$ $\mathrm{cm}$ de diâmetro).

A massa unitária do fruto, assim como o número de pencas e de frutos por cacho, são fatores que interferem na produtividade, embora não detectado diferenças na análise estatística (Tabela 3) em relação ao aumento da densidade de plantio. A manutenção dessa massa em padrões de comercialização, permitiu o ganho expressivo no rendimento do cacho na medida que se aumentava a população de plantas, aspecto importante quando se pretende conduzir pomares de bananeira em um único ciclo de cultivo (Cortazar et al., 2017).

\section{Conclusão}

$\mathrm{O}$ adensamento de plantio aumentou a altura das plantas em pelo menos $50 \mathrm{~cm}$ e o rendimento do cacho em até $263 \%$ (de $13 \mathrm{t} \mathrm{ha}^{-1}$ para $46 \mathrm{t}^{\mathrm{a}}$
${ }^{1}$ ), sem afetar o padrão comercial dos frutos do plátano cv. D'Angola. Altas densidades de plantio podem atrasar a colheita.

\section{Referências}

Almeida, U. O.; Andrade Neto, R. D. C.; Silva, M. M.; Cades, M.; Gomes, R. R. Características físicas e de produção de banana comprida cultivar d'angola em diferentes espaçamentos $\left(1^{\circ}\right.$ ciclo). In: Congresso Brasileiro de Fruticultura, 23, 2014, Cuiabá. Anais... Cuiabá: Sociedade Brasileira de Fruticultura, 2014. CD de

Resumos. https://ainfo.cnptia.embrapa.br/digital/bitstream/item/111 414/1/25274.pdf

Alves, E. J. Cultivo de bananeira tipo Terra. Cruz das Almas: Embrapa Mandioca e Fruticultura, 2001. 176p.

Andrade Neto, R. C.; Almeida, U. O.; Lunz, A. M. P.; Oliveira, T. K.; Nogueira, S. R.; Oliveira, J. R. Características agronômicas de bananeira Terra, cv. D'Angola, em consórcio com açaizeiro (Euterpe precatoria Mart.). Rio Branco: Embrapa Acre, 2015. 18p. (Boletim de Pesquisa, 52). https://ainfo.cnptia.embrapa.br/digital/bitstream/item/136 $\underline{\text { 874/1/25853.pdf }}$

Añez, B.; Tavira, E. Estudio de las densidades de población en las primeras cuatro generaciones del plátano (Musa grupo AAB cv. Hartón). Revista de la Facultad de Agronomía (LUZ), v.16, n.4, p.337-355, 1999. http://revfacagronluz.org.ve/v16_4/v164z004.html

Belalcázar Carvajal, S. L. Altas densidades de siembra en plátano, uma alternativa rentable y sostenible de producción. In: ACORBAT, 15., 2002, Medelin. Anais... Medelin: Associación de Bananeros de Colombia, 2002. CD de Resumos.

Bustamante, A. Análisis sectorial de Plátano 2015: Quito: PROECUADOR. Disponível em: $<\quad$ http://www.proecuador.gob.ec/pubs/analisis-sectorplatano-2015/ >. Acesso em: 30 de novembro de 2017.

Cayón, G.; Valencia, L.; Morales, H.; Domínguez, A. Desarrollo y producción del plátano Dominico-Hartón (Musa AAB Simmonds) en diferentes densidades y arreglos de siembra. Agronomía Colombiana, v.22, n.1, p.18-22, 2004. http://www.redalyc.org/articulo.oa?id=180317823003 
Coelho, E. F.; Oliveira, R. C.; Pamponet, A. J. M. Necessidades hídricas de bananeira tipo Terra em condições de tabuleiros costeiros. Pesquisa Agropecuária Brasileira, v.48, n.9, p.12601268 , 2013. https://seer.sct.embrapa.br/index.php/pab/article/view/157 $\underline{00}$

Cordeiro, Z. J. M. Banana: fitossanidade. Cruz das Almas: Embrapa Mandioca e Fruticultura, 2000. 121p. (Série Frutas do Brasil, 8). http://www.frutvasf.univasf.edu.br/images/banana1.pdf

Cortazar, S. M. U.; Wolf, E. D.; González, I. A. Effect of plant density on growth and yield in Barraganete plantain (Musa paradisiaca (L.) $\mathrm{AAB}$ cv. Curare enano) for a single harvest cutting in Provincia de Los Ríos, Ecuador. Acta Agronómica, v.66, n.3, p.367-372, 2017. https://doi.org/10.15446/acag.v66n3.52198

Dantas, D. J. Características agronômicas de cultivares de bananeira em três ciclos de produção e reação de genótipos a Cosmopolites sordidus no Vale do Açu-RN. 2010. 83 f. Tese (Doutorado em Agronomia) Centro de Ciência Agrárias, Universidade Federal Rural do Semi-Árido, Rio Grande do Norte, Mossoró, UFERSA, 2010.

Delgado, E.; Gómez, N.; González, O.; Marín, C. Evaluación a nivel de finca del efecto de la alta densidad de siembra en plátano (Musa AAB cv. Subgrupo plátano Hartón), municipio Obispo, Barinas, Venezuela. Revista de la Faculdad de Agronomía (LUZ), v.25, p.603-616, 2008. http://www.revfacagronluz.org.ve/PDF/octubre_diciembr e2008/v25n4a20081.pdf

EMBRAPA. Sistema brasileiro de classificação de solos. $3^{\text {a }}$ ed. Rio de Janeiro: Embrapa, 2013. $353 \mathrm{p}$.

Faria, H. C.; Donato, S. L. R.; Pereira, M. C. T.; Silva, S. O. Avaliação fitotécnica de bananeira tipo terra sob irrigação em condições semiáridas. Ciência e Agrotecnologia, v.34, n.4, p.830-836, 2010. http://dx.doi.org/10.1590/S1413-70542010000400006

Ferreira, D.F. Sisvar: a computer statistical analysis system. Ciência e Agrotecnologia, v.35, n.6, p.1039-1042, 2011. http://dx.doi.org/10.1590/S1413-70542011000600001

Lima, L. W. F. Resposta da bananeira cv. D'Angola sob diferentes densidades de plantas, níveis de água e adubação. 2015. 70 f. Dissertação (Mestrado em Agronomia) -
Centro de Ciências Agrárias, Universidade Federal do Recôncavo Baiano, Bahia, Cruz das Almas, 2015.

Lima, L. W. F.; Coelho, E. F.; Queiroz, L. A.; Andrade, T. P.; Melo, D. M.; Batista, L. S. Efeito da adubação e densidade de plantas no crescimento da bananeira cv. D'Angola irrigada. In: INOVAGRI International Meeting, 3., 2015, Fortaleza. Anais... Fortaleza: Instituto INOVAGRI, $2015 . \quad$ p. 815-822. http://dx.doi.org/10.12702/iii.inovagri.2015-a090

Karamura, D.; Ocimati, W.; Ssali, R.; Jogo, W.; Walyawula, S.; Karamura, E. Banana Genotype Composition along the Uganda - Democratic Republic of Congo Border: A Gene Pool Mix for Plantain and Highland Bananas. In: Blomme, G., Vanlauwe, B., van Aster, P. (Ed.). Banana Systems in the Humid Highlands of Sub-Saharan Africa: Enhancing Resilience and Productivity. Boston: $\mathrm{CAB}$ International, 2013. cap. 3, p. 22-29.

Martínez, G.; Blanco, G; Hernández, J.; Manzanilla, E.; Pérez, A.; Pargas, R.; Marín, C. Comportamiento del plátano (Musa AAB Subgrupo plátano, cv. Hartón Gigante) sembrado a diferentes densidades de siembra en el Estado Yaracuy, Venezuela. Revista UDO Agrícola, v.9, n.1, p.259-267, 2009. https://dialnet.unirioja.es/descarga/articulo/3294036.pdf

Moreira, R. S. Banana: teoria e prática de cultivo. Campinas: Cargill, 1987. 335p.

Moreira, A; Heinrichs, R; Pereira, J. C. R. Densidade de plantio na produtividade e nos teores de nutrientes nas folhas e frutos da bananeira cv. Thap Maeo. Revista Brasileira de Fruticultura, v.29, n.3, p.626-631, 2007. http://dx.doi.org/10.1590/S0100-29452007000300039

Moura, R. J. M.; Silva Júnior, J. F.; Santos, V.; Gouveia, J. Espaçamento para o cultivo da bananeira 'comprida verdadeira' (Musa AAB) na zona da Mata Sul de Pernambuco (1 ciclo). Revista Brasileira de Fruticultura, v.24, n.3, p.697-699, 2002. http://dx.doi.org/10.1590/S010029452002000300032

Pereira, M. C. T.; Salomão, L. C. C.; Silva, S. D. O.; Sediyama, C. S.; Couto, F. A. D.; Silva Neto, S. D. Crescimento e produção de primeiro ciclo da bananeira 'Prata Anã' (AAB) em sete espaçamentos. Pesquisa Agropecuária Brasileira, v.35, n.7, p.1377-1387, 2000. 
https://ainfo.cnptia.embrapa.br/digital/bitstream/AI$\underline{\text { SEDE/18076/1/pab98_252.pdf }}$

Rosales, F. E.; Alvarez, J. M.; Vargas, A. Guía prática para La producion de plátano com altas densidades: Experiencias de América Latina y El Caribe. Monpellier: Bioversity Internacional, 2008. 24 p.
Scarpare Filho, J. A.; Kluge, R. A. Produção da bananeira "Nanicão" em diferentes densidades de plantas e sistemas de espaçamento. Revista Brasileira de Fruticultura, v.36, n.1, p.105113, 2001. http://dx.doi.org/10.1590/S0100$\underline{204 X 2001000100013}$ 